\title{
A study on treatment outcomes in MDR-TB patients on long term regimen in West Godavari district
}

\author{
Gedela Vasavi $^{1}$, Banerji Neerugatti ${ }^{2 *}$, Chiranjeevi Uday Kumar ${ }^{1}$, Hari Jagannadha Rao $^{3}$
}

\author{
${ }^{1}$ Associate Professor, ${ }^{3}$ Professor, Department of Pharmacology, ASRAMS Medical College, Eluru, Andhra Pradesh, \\ India \\ ${ }^{2}$ Assistant Professor, Department of Community Medicine, ASRAMS Medical College, Eluru, Andhra Pradesh, India
}

Received: 15 January 2021

Revised: 29 January 2021

Accepted: 30 January 2021

*Correspondence:

Dr. Banerji Neerugatti,

Email: neerugatti.banerji6@gmail.com

Copyright: (C) the author(s), publisher and licensee Medip Academy. This is an open-access article distributed under the terms of the Creative Commons Attribution Non-Commercial License, which permits unrestricted non-commercial use, distribution, and reproduction in any medium, provided the original work is properly cited.

\begin{abstract}
Background: MDR-TB is defined as a TB patient whose biological specimen is resistant to isoniazid and rifampicin with or without resistant to other first line drugs, based on results from quality assured laboratory. The main aim of this study was to study the treatment outcomes of longer regimen for MDR-TB patients.

Methods: This is a retrospective observational cohort study. After obtaining ethical committee approval from Institutional ethics committee, data was collected from district TB centre from 2011-2016. Outcomes of a regimen is measured in terms of cured, treatment completed, number of defaulters, treatment failure, number of patients shifted to XDR-TB regimen, number of patients died for patients on longer regimen of MDR-TB. The collected data was entered in Microsoft excel 2007 and analysed using SPSS version 20 software.

Results: Out of 211 patients, 167 were males and 44 were females. The total numbers of patients registered from rural areas were 123 and from urban areas were 88. The association between geographical distribution and treatment outcome was measured using Chi-square test and $\mathrm{X} 2=12.1026, \mathrm{p}=0.0005$ which was significant. Out of 211 patients registered, $87(41.2 \%)$ were cured of disease, $55(26 \%)$ died, $2(0.9 \%)$ patients shifted to XDR. $18(8.5 \%)$ patients were defined as defaulters and $2(0.9 \%)$ patients were defined as treatment failures.

Conclusions: Our study findings have indicated that treatment outcomes in drug resistant TB may be influenced by rural and urban distribution.
\end{abstract}

Keywords: MDR-TB, XDR-TB, Treatment outcomes

\section{INTRODUCTION}

TB (tuberculosis) is the leading cause of mortality and morbidity. TB kills an estimated 480,000 Indians every year and more than 1,400 every day. India also has more than a million 'missing' cases every year that are not notified and most remain either undiagnosed or unaccountably and inadequately diagnosed and treated in the private sector. RNTCP screens around 20 million TB symptomatic by microscopy and initiates around 1.5 million cases of TB on treatment annually since 2007-08.
In 2016, 520,000 patients have been tested and 35,000 rifampicin resistant/MDR-TB (multi drug resistanttuberculosis) patients have been diagnosed. NSP 20122017 took significant strides in acceleration of MDR TB management country wide. Exponential scale up of programmatic management of drug resistant TB (PMDT) was completed to achieve country wide coverage in March 2013. From 2012-2016, 120,299 DRTB patients have been detected and put 110,808 on treatment (data up to $\mathrm{Q} 3,2016)$. All rifampicin resistant (RR)/multi drug resistant TB patients are subjected to baseline kanamycin and levofloxacin all across the country. The standard 
RNTCP regimen consists of 6 drugs; kanamycin, levofloxacin, ethionamide, cycloserine, pyrazinamide, ethambutol for 6-9 months and 4 drugs; levofloxacin, ethionamide, cycloserine, ethambutol in continuation phase for 18 months. This regimen was used in all confirmed or suspect MDR-TB cases, unless DST results of an individual case necessitate use of an individualised regimen. RR/MDR-TB patients without additional drug resistance are treated with standard short course treatment regimen for MDR TB. And in those with mixed patterns of resistance, standard MDR TB regimens were modified as per revised guidelines. ${ }^{1}$

\section{Objective}

The objective of current study was to study the treatment outcomes of longer regimen for MDR-TB (multi-drug resistant tuberculosis) patients.

\section{METHODS}

\section{Study type, design, population and place}

Current study was a retrospective observational cohort study conducted on patients who were diagnosed, registered and treated with MDR-TB at district TB centre at a tertiary hospital attached to a medical college in West Godavari.

\section{Study duration and sampling method}

Data was collected from year 2011 to 2016 for MDR-TB patients who were on longer regimen. As the study was retrospective, purposive or convenient sampling method was adopted (registered patients at District TB centre, Eluru).

\section{Inclusion and exclusion criteria}

Patients who were diagnosed as MDR-TB according to RNTCP (revised national tuberculosis control programme) guidelines were included in the study. Patients who were not diagnosed as MDR-TB, patients whose data was incomplete and patients who were lost to follow-up were excluded from the study.

\section{Data collection procedure and data analysis}

After obtaining ethical committee approval from institutional ethics committee, data was collected from TB centre in case record forms. The basic demographic data collected was age, sex, and geographical distribution. Outcomes of treatment regimen was measured in terms of cured, treatment completed, number of defaulters, treatment failure, number of patients shifted to XDR-TB (extensively drug resistant tuberculosis) regimen, number of patients died. Treatment outcomes were defined and classified according to the WHO guidelines. ${ }^{2}$ Cured from DR-TB was defined as those who completed treatment within 18 months to over 2 years, followed by at least two negative sputum cultures. Completed treatment was defined as patients who completed the anti TB regimen for at least 18 months. Death was defined as patients who died during treatment whatever the cause. Default is a patient who after treatment has interrupted treatment consecutively for more than 2 months. Data analysis was done using SPSS software for windows version 20.0. All these outcome parameters were expressed as percentages and were compared by bar charts. The association between age, geographical distribution with treatment outcomes was calculated by Chi-square test. The statistical significance level was fixed at $\mathrm{p}<0.05$.

\section{RESULTS}

A total of 211 cases were registered from the year 2011 to 2016 . Out of 211 patients, $167(79.1 \%)$ were males and $44(20.9 \%)$ were females.

Table 1: Sex distribution in the patients.

\begin{tabular}{|llll|}
\hline Year & $\begin{array}{l}\text { Males } \\
\text { N }(\%)\end{array}$ & $\begin{array}{l}\text { Females } \\
\text { N }(\%)\end{array}$ & $\begin{array}{l}\text { Total } \\
\text { N }(\%)\end{array}$ \\
\hline $\mathbf{2 0 1 1}$ & $10(76.9)$ & $3(23.1)$ & $13(100)$ \\
\hline $\mathbf{2 0 1 2}$ & $14(73.7)$ & $5(26.3)$ & $19(100)$ \\
\hline $\mathbf{2 0 1 3}$ & $25(80.6)$ & $6(19.4)$ & $31(100)$ \\
\hline $\mathbf{2 0 1 4}$ & $43(74.1)$ & $15(25.9)$ & $58(100)$ \\
\hline $\mathbf{2 0 1 5}$ & $22(75.9)$ & $7(24.1)$ & $29(100)$ \\
\hline $\mathbf{2 0 1 6}$ & $53(86.9)$ & $8(13.1)$ & $61(100)$ \\
\hline Total & $167(79.1)$ & $44(20.9)$ & $211(100)$ \\
\hline
\end{tabular}

(Figures in the parenthesis refers row total percentage)

Table 2: Association between gender and outcome of study population.

\begin{tabular}{|llll|}
\hline \multirow{2}{*}{ Gender } & \multicolumn{2}{l}{ Final outcome } & Total \\
\hline Males & Dead & Alive & \\
\hline Females & 47 & 120 & 167 \\
\hline Total & 8 & 36 & 44 \\
\hline
\end{tabular}

$X^{2}=1.793, \mathrm{p}=0.180$, not significant.

Table 3: Geographical distribution of the study population.

\begin{tabular}{|llll|}
\hline Year & $\begin{array}{l}\text { Rural } \\
\text { N }(\%)\end{array}$ & $\begin{array}{l}\text { Urban } \\
\text { N }(\%)\end{array}$ & $\begin{array}{l}\text { Total } \\
\text { N }(\%)\end{array}$ \\
\hline $\mathbf{2 0 1 1}$ & $7(53.8)$ & $6(46.2)$ & $13(100)$ \\
\hline $\mathbf{2 0 1 2}$ & $16(84.2)$ & $3(15.8)$ & $19(100)$ \\
\hline $\mathbf{2 0 1 3}$ & $20(64.5)$ & $11(35.5)$ & $31(100)$ \\
\hline $\mathbf{2 0 1 4}$ & $35(60.3)$ & $23(39.7)$ & $58(100)$ \\
\hline $\mathbf{2 0 1 5}$ & $16(55.1)$ & $13(44.9)$ & $29(100)$ \\
\hline $\mathbf{2 0 1 6}$ & $29(47.5)$ & $32(52.5)$ & $61(100)$ \\
\hline Total & $123(58.3)$ & $88(41.7)$ & $211(100)$ \\
\hline
\end{tabular}


The association between gender and final treatment outcome was measured using chi-square test and was found to be statistically not significant as $p>0.05$. The sex distribution was shown year wise (Table1-2). The study population were aged between the range of $20-71$ years with median age of 31 years.

Table 4: Association between geographical distribution and final outcome of patients.

\begin{tabular}{|c|c|c|c|}
\hline & \multicolumn{2}{|c|}{ Final outcome } & \multirow{2}{*}{ Total N (\%) } \\
\hline & Dead & Alive & \\
\hline Rural & 43 & 80 & $123(58.29)$ \\
\hline Urban & 12 & 76 & $88(41.70)$ \\
\hline Total & 55 & 156 & $211(100)$ \\
\hline
\end{tabular}

$X^{2}=12.1026, \mathrm{p}=0.0005$, significant.
The geographical distribution of the study population (rural and urban) was shown year-wise from 2011- 2016 (Table 3-4). The total numbers of patients registered from rural areas were $123(58.3 \%)$ and from urban areas were 88 (41.7\%). The association between geographical distribution and treatment outcome was measured using Chi-square test and was found to be statistically significant $(\mathrm{p}=0.0005)$. This means patients who resided in rural area were observed to have more deaths when compared to the patients who reside in the urban area in our study.

The treatment outcomes of patients were shown yearwise (Table 5). Out of 211 patients registered, 87 (41.2\%) were cured of disease, $55(26 \%)$ died, $2(0.9 \%)$ patients shifted to XDR (extremely drug resistant TB). 18 (8.5\%) patients were defined as defaulters and $2(0.9 \%)$ patients were defined as treatment failures.

Table 5: Treatment outcome of MDR-TB patients (2011-2016).

\begin{tabular}{|llllllll|} 
Year & $\begin{array}{l}\text { Total } \\
\text { registered } \\
\text { N }\end{array}$ & $\begin{array}{l}\text { Cured } \\
\text { N }(\%)\end{array}$ & $\begin{array}{l}\text { Treatment } \\
\text { completed } \\
\text { N }(\%)\end{array}$ & $\begin{array}{l}\text { Died } \\
\text { N }(\%)\end{array}$ & $\begin{array}{l}\text { Defaults } \\
\text { N }(\%)\end{array}$ & $\begin{array}{l}\text { Failure } \\
\text { N }(\%)\end{array}$ & $\begin{array}{l}\text { Switched to } \\
\text { XDR } \\
\text { N }(\%)\end{array}$ \\
\hline $\mathbf{2 0 1 1}$ & 13 & $10(76.9)$ & $0(0)$ & $2(15.3)$ & $1(7.69)$ & $0(0)$ & $0(0)$ \\
\hline $\mathbf{2 0 1 2}$ & 19 & $7(36.8)$ & $4(21)$ & $6(31.5)$ & $2(10.5)$ & $0(0)$ & $0(0)$ \\
\hline $\mathbf{2 0 1 3}$ & 31 & $16(51.6)$ & $2(6.4)$ & $8(25.8)$ & $4(12.9)$ & $0(0)$ & $1(3.2)$ \\
\hline $\mathbf{2 0 1 4}$ & 58 & $19(32.7)$ & $15(25.8)$ & $18(31)$ & $3(5.2)$ & $2(3.4)$ & $1(1.7)$ \\
\hline $\mathbf{2 0 1 5}$ & 29 & $12(41.3)$ & $6(20.6)$ & $8(27.5)$ & $3(10.3)$ & $0(0)$ & $0(0)$ \\
\hline $\mathbf{2 0 1 6}$ & 61 & $24(39.3)$ & $19(31.1)$ & $13(21.3)$ & $5(8.2)$ & $0(0)$ & $0(0)$ \\
\hline Total & 211 & $87(41.2)$ & $46(21.8)$ & $55(26)$ & $18(8.5)$ & $2(0.9)$ & $2(0.9)$ \\
\hline
\end{tabular}

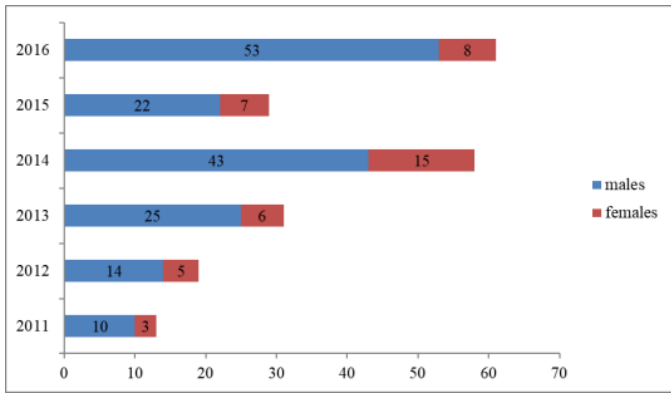

Figure 1: Sex distribution in patients.

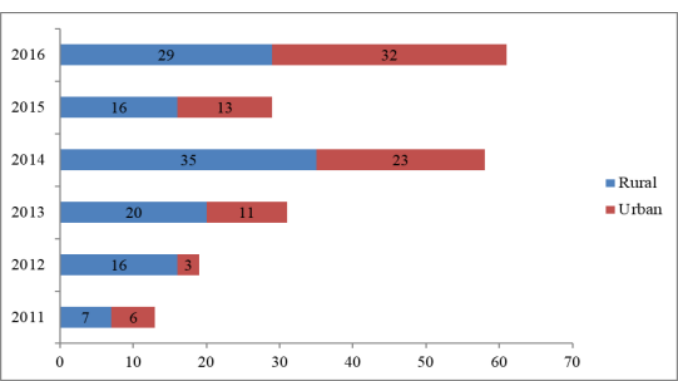

Figure 2: Geographical distribution of the study population.

\section{DISCUSSION}

Treatment of drug resistant TB is much more complex and lengthier in comparison to treatment of drug sensitive TB and requires special care during treatment which is made more cumbersome due to adverse drug reactions. Indian RNTCP is the world's largest DOTS programme achieving global targets of case finding and treatment success rate but the same success has not been achieved with PMDT.

The treatment success rates in India under the programme are well below $50 \%$ with approximately $20 \%$ each death and lost to follow up. ${ }^{3}$ But more recent studies with patients treated under programmatic condition with standardized regimen show better success rate ranging from 54 to $63 \%$ and a lower default rate ranging from 9.2\% to $23 \% .^{4-6}$ The treatment success report in Andhra Pradesh is $50 \%$, percentage who died is $25 \%$, percentage who defaulted is $17 \%$ and percentage who failed treatment is $2 \%{ }^{7}$

Current study results of West Godavari district, treatment success rates are $41.2 \%$ which is in par with annual TB report of India. The percentage of death is $26 \%$ which is higher and the default percentage is $8.5 \%$ which is lower 
than Annual TB report. A meta-analysis of several studies from 23 countries by Ahuja et al showed that success rate was variable with overall success rate $54 \%$ and default rate $23 \%{ }^{8}$

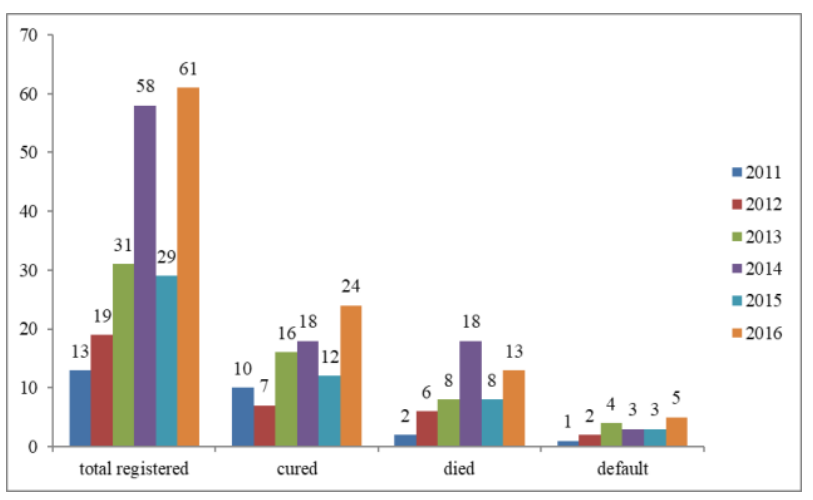

Figure 3: Treatment outcome of MDR-TB patients (2011-2016).

A more recent meta-analysis by Kibret et al found successful outcome in $63.5 \%$ cases but success rate was low among patients treated with standardized second line regimen compared to those treated with individualized regimen. ${ }^{9}$ In the present study all the patients are treated with standardized second line drugs as per PMDT guideline. We also observed that urban patients have more success rate than rural patients. The association between geographical distribution and final treatment outcome of patients was found significant by Chi-square test. In another Indian study done by Agarwalla et al rural patients had both low success rate (53\% vs. 33\%) and high default rate $(23 \%$ vs. $30 \%) .{ }^{10}$ There are certain limitations for this study. As it is a retrospective study, we could not collect much data about life style of individual patients like tobacco smoking, alcohol which can cause much side-effects with long term regimen for MDR-TB.

\section{CONCLUSION}

The present study which is done on the DOTS plus programme in West Godavari district shows a below average success rate. It also showed less success rate in rural areas. This could be due to lack of awareness and lack of education towards TB. So, strengthening of programme in rural areas is necessary. As this was a retrospective study, we could not collect personal data of patient which could help in finding out the root cause of increased failure rate of treatment of $\mathrm{TB}$ in rural population. So, these facts should be further validated by further studies in large number of patients.

Funding: No funding sources Conflict of interest: None declared

Ethical approval: The study was approved by the Institutional Ethics Committee

\section{REFERENCES}

1. Revised National tuberculosis control programme, National strategic plan for tuberculosis elimination 2017-2025. Available at: https://tbcindia.gov.in/ WriteReadData/NSP\%20Draft\%2020.02.2017\%201. pdf. Accessed on 20 September 2020.

2. WHO. Definitions and reporting framework for tuberculosis-2013 revision. Available at: https://www.who.int/tb/publications/definitions/en/. Accessed on 20 September 2020.

3. Annual $\mathrm{Tb}$ report 2016. Available at: https://www.who.int/teams/global-tuberculosisprogramme/tb-reports. Accessed on 20 September 2020.

4. Janmeja A, Aggarwal D, Dhillon R. Analysis of treatment outcome in multi-drug resistant tuberculosis patients treated under programmatic conditions. Int J Res Med Sci. 2017;5:2401.

5. Nair D, Velayutham B, Kannan T, Tripathy J, Harries A, Natrajan $M$, et al. Predictors of unfavourable treatment outcome in patients with multidrug resistant tuberculosis in India. Public Health Action 2017;7:32-8.

6. Desai M, Jain K, Solanki R, Dikshit R. Treatment outcome of standardized regimen in patients with multidrug resistant tuberculosis. J Pharmacol Pharmacother. 2014;5:145.

7. TB India 2016, revised National $\mathrm{Tb}$ control programme, annual status report. Available at: https://tbcindia.gov.in/index1.php?lang=1\&level=2\& sublinkid $=4569 \&$ lid $=3174$. Accessed on 20 September 2020.

8. Ahuja S, Ashkin D, Avendano M, Banerjee R, Bauer $\mathrm{M}$, Bayona $\mathrm{J}$, et al. Multidrug resistant pulmonary tuberculosis treatment regimensand patient outcomes: An individual patient data meta-analysis of 9,153 patients. PLoS Med. 2012;9(8):e1001300.

9. Kibret $\mathrm{K}$, Moges $\mathrm{Y}$, Memiah P, Biadgilign S. Treatment outcomes for multidrug resistant tuberculosis under DOTS Plus: A systematic review and meta-analysis of published studies. Infect Dis Poverty. 2017;6:7

10. Agarwalla A, Bhattacharya S, Dey A, Kar S, Chaudhuri AD. Study of outcome of management of MDR-TB cases under programmatic condition in India. J NTR Univ Health Sci. 2019;8:1-4.

Cite this article as: Vasavi G, Neerugatti B, Kumar CU, Rao HJ. A study on treatment outcomes in MDR-TB patients on long term regimen in West Godavari district. Int J Basic Clin Pharmacol 2021;10:266-9. 